\title{
Co-expression network analysis prioritizes signaling pathways regulating liver regeneration after partial hepatectomy in rats
}

\author{
Y. Zhou ${ }^{1,2}$, J.C. $X u^{1}$ and C.S. $X u^{2}$ \\ ${ }^{1}$ Engineering Technology Research Center for Computing Intelligence \& Data Mining, \\ College of Computer and Information Engineering, Henan Normal University, \\ Xinxiang, Henan, China \\ ${ }^{2}$ Key Laboratory of Cell Differentiation and Regulation, College of Life Science, \\ Henan Normal University, Xinxiang, Henan, China \\ Corresponding author: Y. Zhou \\ E-mail: zy@htu.cn \\ Genet. Mol. Res. 15 (2): gmr.15027596 \\ Received September 9, 2015 \\ Accepted December 2, 2015 \\ Published April 4, 2016 \\ DOI http://dx.doi.org/10.4238/gmr.15027596
}

\begin{abstract}
The liver has extraordinary powers of regeneration following partial hepatectomy $(\mathrm{PH})$. Changes in gene expression levels play a key role in cell proliferation and differentiation during liver regeneration (LR). To understand the molecular mechanisms underlying LR, this study was designed to assess the time-dependent changes in rat hepatic gene expression. We obtained a gene expression profile of rat LR with high temporal resolution. We then constructed gene co-expression networks of regenerating liver tissue and identified 13 LR-specific modules from 1772 differentially expressed genes, and prioritized signaling pathways that regulated $\mathrm{LR}$ after $\mathrm{PH}$. The results indicated that adipocytokine signaling, histone acetylation, and IL-6-related pathways play an important role in LR. Co-expression network analysis provides novel insight into understanding the molecular mechanisms behind LR.
\end{abstract}

Key words: Adipocytokine; Histone acetylation; IL-6; Liver regeneration; Partial hepatectomy 


\section{INTRODUCTION}

The liver plays a central role in metabolic homeostasis and has enormous regenerative capacity within the body (Taub, 2004; Fausto et al., 2006; Michalopoulos, 2007. The prodigious regenerative capability of the liver remains a fascinating research topic for biologists. Liver regeneration $(\mathrm{LR})$ following partial hepatectomy $(\mathrm{PH})$ has been studied extensively since the 19 th century, but the mechanisms underlying this phenomenon are unclear. This regeneration capability can be utilized in clinical scenarios, such as liver tumor resection and living donor liver transplantation (Haga et al., 2008). Therefore, the investigation of the regenerative mechanisms of the liver is highly relevant to hepatic regenerative medicine (Fausto and Riehle, 2005).

The rat $2 / 3 \mathrm{PH}$ model is well-established and is used extensively in the investigation of potential LR molecular mechanisms. Many attempts have been made to study the molecular mechanisms of LR systemically and comprehensively using modern high-throughput biology techniques such as microarray analysis (Togo et al., 2004; Xu et al., 2012). Gene expression analysis by microarray is now a well-established approach in high-throughput biology. As costs per array continue to decrease, temporal resolution in such studies has increased, thereby allowing the more precise investigation of gene expression regulation (Kiddle et al., 2010). After obtaining a high-resolution temporal gene expression profile of rat LR - for example at $0,2,6,12,24,30$, $36,72,120$, and $168 \mathrm{~h}$ - a central task in the exploratory analysis of these high-dimensional time series is to identify the subsets of genes that are functionally related, and to investigate which signaling pathways are responsible for regulating LR. We attempted to resolve these problems by using network-based approaches to identify the important regulatory pathways that control the regeneration process.

Gene co-expression network analysis is an increasingly popular tool for investigating microarray data, particularly for detecting functional gene modules (Horvath and Dong, 2008; Ruan et al., 2010; He et al., 2011, 2012). In this study, the general framework for weighted gene coexpression network analysis (WGCNA) (Zhang and Horvath, 2005) was used to define the gene expression network topology of the regenerating liver. Hierarchical average linkage clustering based on topological overlap (TO) was used to group genes with very similar co-expression patterns into modules (Ravasz et al., 2002). To this end, we identified 13 LR-specific modules that had highly correlated expression levels across samples. Because co-expression modules often correspond to biological pathways (MacLennan et al., 2009), focusing on the analysis of modules allows us to find novel pathways that regulate LR. This study provides new insight into understanding the molecular mechanisms of LR.

\section{MATERIAL AND METHODS}

\section{Data sets}

The livers of healthy adult Sprague-Dawley rats were used as experimental materials. The details of the liver regeneration, RNA extraction, microarray hybridization, and reverse transcriptionpolymerase chain reaction (RT-PCR) validation have been described in an earlier publication (Knepp et al., 2003). Ultimately, we obtained two datasets: one from a PH group and one from a sham-operation (SO) group. The raw and processed microarray data have been deposited in the National Center for Biotechnical Information (NCBI) Gene Expression Omnibus (GEO) database (accession number GSE63742). 


\section{Microarray processing}

The images were converted to signal values using the Affymetrix GeneChip ${ }^{\circledR}$ Operating Software (GCOS) v2.0 (Santa Clara, CA, USA). Signal values for each chip were then normalized, and the gene's relative value was evaluated by the ratio of the normalized signal value of the $\mathrm{PH}$ group to that of the control group. For example, a gene with relative value $>3$ and $P$ value $<0.01$ was regarded as having upregulated expression; a gene with relative value $<0.33$ and $P$ value $<0.01$ was downregulated. To minimize technical error from the microarray analysis, regeneration of the liver at each time-point was repeated three times with the Rat Genome 2302.0 microarray. The raw and processed microarray data are available at the NCBI GEO database (accession number GSE63742).

\section{Co-expression network construction}

The weighted network analysis begins with a matrix of the Pearson correlations between all gene pairs, then converts the correlation matrix into an adjacency matrix using a power function $f(x)=x^{\wedge} \beta$. The parameter of the power function is determined in such a way that the resulting adjacency matrix (i.e., the weighted co-expression network) is approximately scale-free. To measure how well a network satisfied a scale-free topology, we used the fitting index (Zhang and Horvath, 2005) (i.e., the model fitting index $R^{2}$ of the linear model that regresses $\log (p(k))$ on $\log (k)$ where $k$ is connectivity and $p(k)$ is the frequency distribution of connectivity). The fitting index of a perfect scale-free network is 1 . For each data set, we selected the smallest $\beta$ that led to an approximately scale-free network. The distribution $p(k)$ of the resulting network approximates a power law: $p(k) \sim k^{\gamma}$. Then, the Pearson's correlation matrix for each co-expression network is used to calculate the TO (Langfelder et al., 2008), which considers not only the correlation of the two genes, but also their shared neighbors across the whole network.

\section{RESULTS}

\section{Identification of differentially expressed genes}

To assess differentially expressed (DE) genes, we adopted the ImFit function provided in the $\mathrm{R}$ limma package (Smyth, 2004), in which a multiple-linear model is fitted to the expression data for each gene and a t-score is assigned to each gene that quantifies the significance of DE genes by adopting the Benjamini and Hochberg multiple-testing correction scheme. This process identified 1772 genes (Table S1) that were differentially expressed between the $\mathrm{PH}$ group and the SO group (adjusted $\mathrm{P}$ value <0.01) from 31,099 probe sets. Among those genes, 619 genes were upregulated (fold-change $>3$ ) and 307 genes were downregulated (fold-change $<1 / 3$ ) for at least one time-point during LR. We then performed enrichment of biological functions in the upregulated and downregulated genes using GO biological process-enrichment analysis (Table 1). The majority of the biological processes enriched by the upregulated genes are associated with regulation of cell cycles, such as the mitotic cell cycle, cell proliferation, cell division, DNA replication, G1-S transition of the mitotic cell cycle, organ regeneration, and apoptosis. Other processes not directly involved in the cell cycle, such as inflammatory response, immune response, response to organic cyclic compounds, hypoxia, mechanical stimulus, and glucocorticoid stimulus, are also enriched. The authors of previous research have reported that immune response and inflammatory phenotypes 
play an important role in LR (limuro et al., 2007), and our results further suggested that these two processes are probably important causes of LR. The downregulated genes are significantly enriched for processes associated with metabolism (e.g., lipid and fatty acid metabolic processes).

Table 1. Functional annotations enriched in upregulated genes(leftcolumn)and downregulated genes (right column).

\begin{tabular}{|c|c|c|c|c|c|c|c|}
\hline Upregulated genes & Set & Overlap & $P$ value & Downregulated genes & Set & Overlap & $P$ value \\
\hline Cell cycle & 604 & 77 & $1.65 \mathrm{E}-46$ & Metabolic process & 2421 & 125 & $1.23 \mathrm{E}-56$ \\
\hline Mitotic cell cycle & 316 & 57 & $5.99 \mathrm{E}-43$ & Oxidation-reduction process & 840 & 69 & $2.85 \mathrm{E}-42$ \\
\hline Cell division & 336 & 53 & 7.57E-37 & Xenobiotic metabolic process & 152 & 30 & $5.56 \mathrm{E}-30$ \\
\hline Mitosis & 252 & 47 & $3.24 \mathrm{E}-36$ & Lipid metabolic process & 372 & 35 & $1.80 \mathrm{E}-23$ \\
\hline M phase of mitotic cell cycle & 96 & 27 & 2.05E-26 & Glutathione metabolic process & 43 & 15 & $9.82 \mathrm{E}-20$ \\
\hline Mitotic prometaphase & 90 & 24 & $5.28 \mathrm{E}-23$ & Cellular nitrogen compound metabolic process & 209 & 25 & 1.36E-19 \\
\hline Response to drug & 484 & 45 & 1.29E-21 & Lipid biosynthetic process & 128 & 18 & $1.03 \mathrm{E}-15$ \\
\hline Inflammatory response & 316 & 35 & $1.78 \mathrm{E}-19$ & Fatty acid metabolic process & 118 & 17 & $4.31 \mathrm{E}-15$ \\
\hline $\begin{array}{ll}\text { Response } & \text { to } \\
\text { lipopolysaccharide } & \\
\end{array}$ & 193 & 27 & $6.60 \mathrm{E}-18$ & Cellular lipid metabolic process & 141 & 17 & 8.87E-14 \\
\hline DNA replication & 179 & 26 & $1.05 \mathrm{E}-17$ & Protein homotetramerization & 51 & 11 & $3.13 \mathrm{E}-12$ \\
\hline $\begin{array}{l}\text { Cytokine-mediated } \\
\text { signaling pathway }\end{array}$ & 228 & 27 & 4.86E-16 & Response to drug & 484 & 24 & $2.02 \mathrm{E}-10$ \\
\hline Chemotaxis & 153 & 22 & 4.35E-15 & $\begin{array}{l}\text { Positive regulation of fatty acid biosynthetic } \\
\text { process }\end{array}$ & 12 & 6 & 8.92E-10 \\
\hline $\begin{array}{l}\text { G1-S transition of mitotic } \\
\text { cell cycle }\end{array}$ & 154 & 22 & $5.00 \mathrm{E}-15$ & Steroid metabolic process & 120 & 12 & 3.66E-09 \\
\hline $\begin{array}{l}\text { Response to organic cyclic } \\
\text { compound }\end{array}$ & 234 & 26 & $8.01 \mathrm{E}-15$ & Glucose metabolic process & 134 & 12 & $1.29 \mathrm{E}-08$ \\
\hline Cell cycle checkpoint & 141 & 21 & $8.91 \mathrm{E}-15$ & Xenobiotic catabolic process & 10 & 5 & $2.47 \mathrm{E}-08$ \\
\hline $\begin{array}{l}\text { Response to DNA damage } \\
\text { stimulus }\end{array}$ & 309 & 29 & $1.90 \mathrm{E}-14$ & $\begin{array}{l}\text { Branched chain family amino acid catabolic } \\
\text { process }\end{array}$ & 21 & 6 & 4.85E-08 \\
\hline DNA repair & 337 & 30 & $2.73 \mathrm{E}-14$ & Carbohydrate metabolic process & 369 & 18 & $5.03 \mathrm{E}-08$ \\
\hline Organ regeneration & 87 & 17 & $3.11 \mathrm{E}-14$ & Triglyceride biosynthetic process & 36 & 7 & $6.54 \mathrm{E}-08$ \\
\hline Immune response & 523 & 37 & $3.59 \mathrm{E}-14$ & Cholesterol metabolic process & 81 & 9 & 1.35E-07 \\
\hline $\begin{array}{l}\text { DNA strand elongation } \\
\text { involved in DNA replication }\end{array}$ & 35 & 12 & $1.23 \mathrm{E}-13$ & Ethanol oxidation & 14 & 5 & 1.90E-07 \\
\hline S phase of mitotic cell cycle & 120 & 18 & $6.53 \mathrm{E}-13$ & Response to toxin & 111 & 10 & $2.02 \mathrm{E}-07$ \\
\hline Response to hypoxia & 241 & 24 & $9.75 \mathrm{E}-13$ & Aging & 178 & 12 & $2.98 \mathrm{E}-07$ \\
\hline Aging & 178 & 21 & $9.76 \mathrm{E}-13$ & Fatty acid biosynthetic process & 89 & 9 & 3.07E-07 \\
\hline Apoptosis & 778 & 43 & 1.37E-12 & $\begin{array}{l}\text { Positive regulation of triglyceride catabolic } \\
\text { process }\end{array}$ & 7 & 4 & $3.50 \mathrm{E}-07$ \\
\hline $\begin{array}{l}\text { Response to mechanical } \\
\text { stimulus }\end{array}$ & 84 & 15 & $4.06 \mathrm{E}-12$ & Biosynthetic process & 75 & 8 & 9.33E-07 \\
\hline $\begin{array}{l}\text { Response to glucocorticoid } \\
\text { stimulus }\end{array}$ & 134 & 18 & $4.50 \mathrm{E}-12$ & Cellular amino acid metabolic process & 77 & 8 & $1.14 \mathrm{E}-06$ \\
\hline Chromosome segregation & 75 & 14 & $1.13 \mathrm{E}-11$ & Response to nutrient & 135 & 10 & $1.24 \mathrm{E}-06$ \\
\hline $\begin{array}{l}\text { Phosphatidylinositol- } \\
\text { mediated signaling }\end{array}$ & 77 & 14 & $1.64 \mathrm{E}-11$ & Brown fat cell differentiation & 35 & 6 & $1.29 \mathrm{E}-06$ \\
\hline Blood coagulation & 477 & 31 & $3.91 \mathrm{E}-11$ & Liver development & 109 & 9 & $1.73 \mathrm{E}-06$ \\
\hline Regulation of cell cycle & 99 & 15 & $4.76 \mathrm{E}-11$ & Water-soluble vitamin metabolic process & 58 & 7 & $1.95 \mathrm{E}-06$ \\
\hline Cell proliferation & 429 & 29 & $6.66 \mathrm{E}-11$ & Bile acid metabolic process & 38 & 6 & $2.14 \mathrm{E}-06$ \\
\hline Anti-apoptosis & 243 & 21 & $3.68 \mathrm{E}-10$ & Methylation & 144 & 10 & $2.24 \mathrm{E}-06$ \\
\hline $\begin{array}{lll}\begin{array}{l}\text { Negative } \\
\text { apoptosis }\end{array} & \text { regulation of } \\
\end{array}$ & 297 & 23 & $4.71 \mathrm{E}-10$ & Cholesterol homeostasis & 61 & 7 & 2.75E-06 \\
\hline
\end{tabular}

The enrichment results were highly consistent with existing knowledge and our previous research into the regeneration of rat hepatocytes, which are the primary participants in LR (Zhou et al., 2014). This suggests that the DE genes are repeatable and can be used as reference genes for new pathways and for key regulator identification. 


\section{Co-expression network construction and identification of co-expression patterns}

The expression patterns of genes that are influenced by a certain regulator tend to be similar (Segal et al., 2003). To explore the co-expression patterns of DE genes, we performed an integrative investigation using WGCNA, which has shown that TO leads to more cohesive and biologically meaningful modules (Ravasz et al., 2002; Zhang and Horvath, 2005).

The use of WGCNA to identify gene expression patterns for prioritizing gene targets is increasing. WGCNA is a biological system method for describing the correlation patterns among genes across microarray samples. Networks are simple graphical models comprising nodes and edges. In a gene co-expression network, the nodes represent genes, and edges between any two nodes indicate a relationship (a similar expression pattern) between the two corresponding genes. One important end product of WGCNA is gene modules comprising highly interconnected sets of genes. It has been demonstrated that these types of module are generally enriched for known biological pathways (Schadt et al., 2005; Gargalovic et al., 2006; Chen et al., 2012).

A gene co-expression network can be fully represented by a topological overlap matrix (TOM). TO between two genes not only reflects their more proximal interactions (e.g., two genes physically interacting or having correlated expression values), but also reflects the higher-order interactions that these two genes may have with other genes in the network. Following a previously described method of WGCNA, two co-expression networks - one for the PH group and the other for the SO group - were constructed. Briefly, we began by calculating the Pearson correlations for all pairs of genes in the network. Next, the Pearson's correlation matrix for each co-expression network was transformed into a matrix of connection strengths using a power function $\left(f(x)=x^{\wedge} \beta\right)$; here we chose $\beta=12$ in accordance with the scale-free topology criterion (Zhang and Horvath, 2005). We then used these connection strengths to calculate the TO. The TOM plots of the PH networks are depicted in Figure 1. A complete description of the methods used can be found in the Material and Methods section.

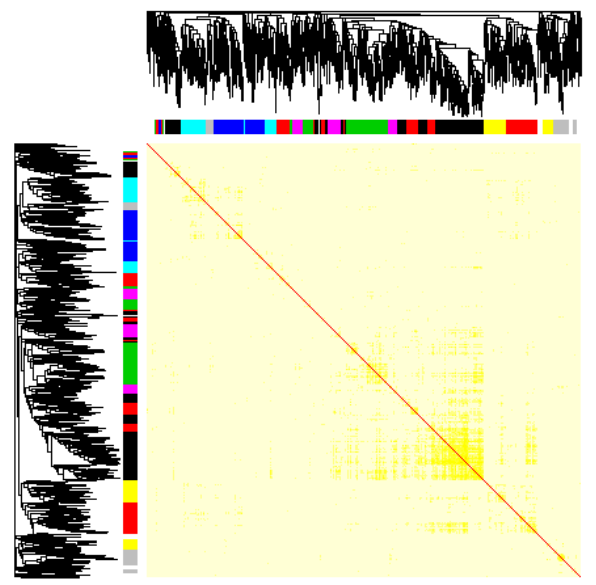

Figure 1. Topological overlap matrix (TOM) plots of weighted gene co-expression networks constructed from microarray analyses. Each symmetric heat map with rows and columns as genes represents the network connection strength between any pair of nodes (genes) in the corresponding network. The network connection strength is measured as the topological overlap between genes. The network modules highlighted as color blocks along the rows and columns (each color block represents a module) were identified via an average linkage hierarchical clustering algorithm using topological overlap as the dissimilarity metric. To distinguish between modules, each module was assigned a unique color identifier, with the remaining, poorly connected genes colored gray. 
Then, hierarchical average linkage clustering based on TO was performed to identify gene co-expression modules, that is, groups of genes with similar patterns of expression across experimental samples. In this way, 16 and 12 modules were identified from the PH and SO groups, respectively. The module composition of the $\mathrm{PH}$ and $\mathrm{SO}$ groups is provided in Table S2. Figure 2 shows turquoise and blue module heat maps. It can be seen that the expression pattern of these modules includes both positive and negative correlation patterns. This is consistent with the principle that a regulator can positively and negatively influence the downstream target genes simultaneously.
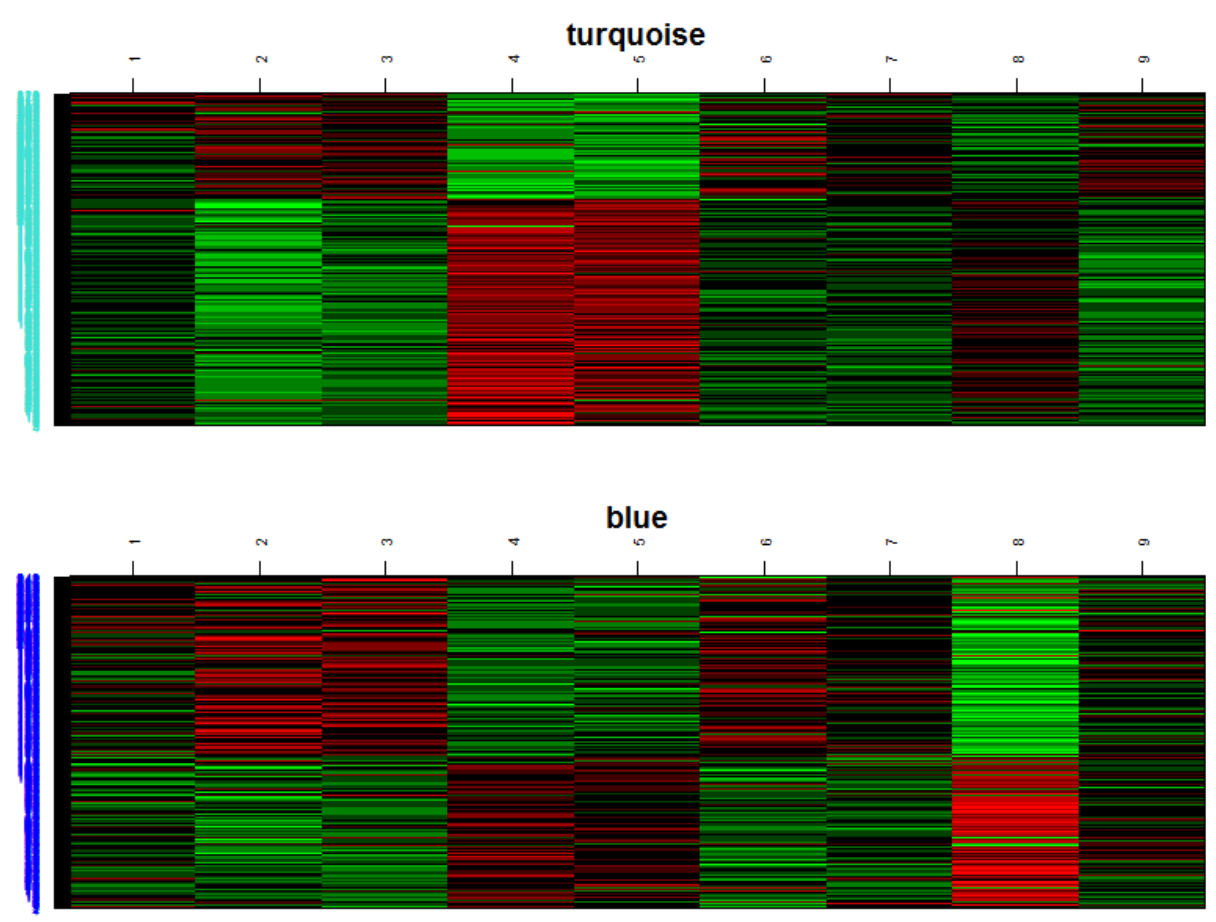

Figure 2. Heat map of average expression of turquoise and blue modules in partial hepatectomy.

\section{Identification of LR-specific gene modules}

We identified gene co-expression modules from the $\mathrm{PH} / \mathrm{SO}$ livers and discovered a distinct module expression pattern in the $\mathrm{PH}$ group. To focus on small subsets of the modules that are most relevant to LR, we also identified LR-specific gene modules, defined as modules with no significant overlap between the $\mathrm{PH}$ and $\mathrm{SO}$ groups at a $\mathrm{P}$ value $<1 \mathrm{e}-50$. Therefore, to evaluate the overlap significance of pairwise modules between the $\mathrm{PH}$ and $\mathrm{SO}$ groups we adopted the Fisher exact test. A graphical illustration of the overlap significance of modules is shown in Figure 3 . For the $\mathrm{PH}$ modules, three modules (pink, yellow, and magenta) of the 16 modules had significant overlap $(P<1 e-50)$ with at least one module derived from the SO group providing reproducibility confidence. We reasoned that those common subsets of genes do not lead to LR, because those module structures did not change during LR. However, other modules that only existed in the $\mathrm{PH}$ group were referred to as LR-specific modules. 


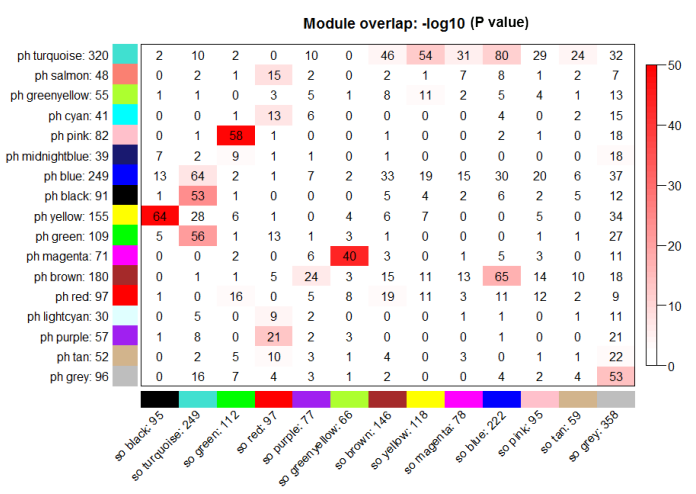

Figure 3. Significance of pairwise module-module overlap. Each row of the table corresponds to one partial hepatectomy $(\mathrm{PH})$-specific module (labeled by color as well as text), and each column corresponds to one shamoperation (SO) module. Numbers in the table indicate gene counts in the intersection of the corresponding modules. Significance of pairwise module-module overlap is based on Fisher exact test $\mathrm{P}$ values. Coloring of the table encodes $-\log (P$ value $)$. The stronger the red color, the more significant the overlap.

\section{Pathway-enrichment analysis}

As well as investigating LR-related modules in terms of gene composition and functional annotation, we also examined the biological relevance of LR-specific modules. Pathway-enrichment analysis of the genes in these modules was carried out using Pathway Studio. Pathway Studio is a pathway analysis tool supplied by the ResNet Mammalian Database that harvests the latest information from literature deposited atand other public sources. The software also uses a number of public and commercial databases such as the Kyoto Encyclopedia of Genes and Genomes (KEGG) database (http://www.genome.jp/kegg/). We selected cell process pathways, cell signaling pathways, metabolic pathways, immunological pathways, and receptor signaling pathways for each module pathway-enrichment analysis. The results are shown in Table 2 (detailed list in Table S3).

All 13 modules were significantly enriched with at least one pathway. The "turquoise" module containing 320 genes shows enrichment in adipocytokine signaling, tryptophan metabolism, glutathione metabolism, and lipoyl-protein complex biosynthesis. Interestingly, $61.54 \%$ of adipocytokine-signaling genes were enriched in the "turquoise" module. We also found that adipocytokine signaling was significantly increased in the LR-specific module of regenerating hepatocytes in an earlier study (Zhou et al., 2014), which supported the reproducibility of the results at the tissue and cellular levels. The "salmon" module with 48 genes shows enrichment in TGFBR-related signaling, which is involved in many cellular processes including cell growth, cell differentiation, apoptosis, cellular homeostasis, and other cellular functions. The "greenyellow" module containing 55 genes shows enrichment in ubiquitin-dependent protein degradation, transcytosis, MHC1-mediated antigen presentation, and presentation of endogenous peptide antigens. Ubiquitin-proteasome-dependent protein degradation plays a critical role in numerous essential cellular processes, including cell cycle progression, apoptosis, and DNA repair. Liver growth induced by partial hepatectomy of the liver is a precisely regulated process, during which a radical reorganization of metabolism occurs as the hepatocytes become committed to enter the cell cycle. Recent studies have shown the importance of the endocytic compartment in the control of lipid and protein intracellular trafficking, as well as in the control of signal transduction events, which eventually trigger the initiation of DNA synthesis and subsequent cell division. 
Table 2. Top-ranked pathways enriched in liver regeneration-specific modules.

\begin{tabular}{|c|c|c|c|c|c|c|c|}
\hline Module & Name & Entities & Overlap & $\begin{array}{l}\text { Percent } \\
\text { overlap }\end{array}$ & $P$ value & $\begin{array}{l}\text { Jaccard } \\
\text { similarity }\end{array}$ & Hit type \\
\hline \multirow[t]{2}{*}{ Black } & $\begin{array}{l}\text { Tight junction assembly } \\
\text { (occludin) }\end{array}$ & 38 & 12 & $31.58 \%$ & 1.09E-05 & 0.0317 & $\begin{array}{l}\text { Cell process } \\
\text { pathways }\end{array}$ \\
\hline & Cell cycle regulation & 135 & 28 & $20.74 \%$ & $4.66 \mathrm{E}-05$ & 0.0125 & Cell signaling \\
\hline Blue & $\begin{array}{l}\text { Metabolism of estrogens and } \\
\text { androgens }\end{array}$ & 116 & 10 & $8.62 \%$ & 0.001398 & 0.0211 & $\begin{array}{l}\text { Metabolic } \\
\text { pathways }\end{array}$ \\
\hline \multirow[t]{4}{*}{ Brown } & Adipocytokine signaling & 52 & 18 & $34.62 \%$ & 0.002091 & 0.0187 & Cell signaling \\
\hline & $\begin{array}{l}\text { Tight junction assembly } \\
\text { (occludin) }\end{array}$ & 38 & 6 & $15.79 \%$ & 0.011651 & 0.0124 & $\begin{array}{l}\text { Cell process } \\
\text { pathways }\end{array}$ \\
\hline & AGER $\rightarrow$ NF-kB signaling & 14 & 2 & $14.29 \%$ & 0.014042 & 0.0088 & $\begin{array}{l}\text { Receptor } \\
\text { signaling }\end{array}$ \\
\hline & $\begin{array}{l}\text { IL15R } \\
\text { signaling }\end{array} \rightarrow$ NF-кB/NFATC & 15 & 2 & $13.33 \%$ & 0.014853 & 0.0088 & $\begin{array}{l}\text { Receptor } \\
\text { signaling }\end{array}$ \\
\hline Cyan & IL-6 promotes inflammation & 39 & 4 & $10.26 \%$ & 0.000189 & 0.0237 & Cell signaling \\
\hline \multirow[t]{5}{*}{ Green } & $\begin{array}{l}\text { Vitamin B5 metabolism and } \\
\text { biosynthesis of CoA and holo- } \\
\text { ACP }\end{array}$ & 35 & 3 & $8.57 \%$ & 0.000929 & 0.0178 & $\begin{array}{l}\text { Metabolic } \\
\text { pathways }\end{array}$ \\
\hline & $\begin{array}{l}\text { Immunoglobulin class-switch } \\
\text { recombination }\end{array}$ & 15 & 3 & $20.00 \%$ & 0.000957 & 0.0201 & $\begin{array}{l}\text { Immunological } \\
\text { pathways }\end{array}$ \\
\hline & $\begin{array}{ll}\begin{array}{l}\text { double-strand } \\
\text { homologous repair }\end{array} & \text { DNA } \\
\end{array}$ & 30 & 6 & $20.00 \%$ & 0.001975 & 0.0197 & $\begin{array}{l}\text { Cell process } \\
\text { pathways }\end{array}$ \\
\hline & DCIR1 (CLEC4A) Signaling & 13 & 4 & $30.77 \%$ & 0.002638 & 0.0204 & $\begin{array}{l}\text { Immunological } \\
\text { pathways }\end{array}$ \\
\hline & $\begin{array}{ll}\text { lipoyl-protein } & \text { complex } \\
\text { biosynthesis } & \\
\end{array}$ & 13 & 2 & $15.38 \%$ & 0.003531 & 0.0137 & $\begin{array}{l}\text { Metabolic } \\
\text { pathways }\end{array}$ \\
\hline \multirow[t]{4}{*}{ Greenyellow } & $\begin{array}{l}\text { Ubiquitin-dependent protein } \\
\text { degradation }\end{array}$ & 13 & 5 & $38.46 \%$ & 1.64E-05 & 0.0291 & $\begin{array}{l}\text { Cell process } \\
\text { pathways }\end{array}$ \\
\hline & Transcytosis & 60 & 5 & $8.33 \%$ & 1.79E-05 & 0.0287 & $\begin{array}{l}\text { Cell process } \\
\text { pathways }\end{array}$ \\
\hline & $\begin{array}{l}\text { MHC1-mediated antigen } \\
\text { presentation }\end{array}$ & 20 & 5 & $25.00 \%$ & 3.69E-05 & 0.0316 & $\begin{array}{l}\text { Immunological } \\
\text { pathways }\end{array}$ \\
\hline & $\begin{array}{l}\text { Presentation of endogenous } \\
\text { peptide antigen }\end{array}$ & 16 & 4 & $25.00 \%$ & 4.31E-05 & 0.0313 & $\begin{array}{l}\text { Cell process } \\
\text { pathways }\end{array}$ \\
\hline Lightcyan & Tight junction regulation & 5 & 2 & $40.00 \%$ & 0.012254 & 0.0194 & Cell signaling \\
\hline \multirow[t]{3}{*}{ Midnightblue } & T-cell receptor signaling & 71 & 4 & $5.63 \%$ & 0.027865 & 0.0099 & $\begin{array}{l}\text { Immunological } \\
\text { pathways }\end{array}$ \\
\hline & EphrinR $\rightarrow$ actin signaling & 15 & 3 & $20.00 \%$ & 0.039594 & 0.0119 & $\begin{array}{l}\text { Receptor } \\
\text { signaling }\end{array}$ \\
\hline & Melanogenesis & 50 & 5 & $10.00 \%$ & 0.046011 & 0.0069 & Cell signaling \\
\hline \multirow[t]{2}{*}{ Purple } & $\begin{array}{l}\text { Metabolism of estrogens and } \\
\text { androgens }\end{array}$ & 116 & 5 & $4.31 \%$ & 0.000633 & 0.0187 & $\begin{array}{l}\text { Metabolic } \\
\text { pathways }\end{array}$ \\
\hline & IL-6 in insulin resistance & 36 & 6 & $16.67 \%$ & 0.00263 & 0.0133 & Cell signaling \\
\hline \multirow[t]{3}{*}{ Red } & $\begin{array}{l}\text { Secretory pathway: Golgi } \\
\text { transport }\end{array}$ & 36 & 5 & $13.89 \%$ & 0.002688 & 0.0141 & $\begin{array}{l}\text { Cell process } \\
\text { pathways }\end{array}$ \\
\hline & Polysaccharide degradation & 20 & 2 & $10.00 \%$ & 0.013076 & 0.0145 & $\begin{array}{l}\text { Metabolic } \\
\text { pathways }\end{array}$ \\
\hline & IL-11R $\rightarrow$ STAT3 signaling & 6 & 1 & $16.67 \%$ & 0.02398 & 0.0085 & $\begin{array}{l}\text { Receptor } \\
\text { signaling }\end{array}$ \\
\hline \multirow[t]{3}{*}{ Salmon } & TGFBR $\rightarrow$ AP-1 signaling & 16 & 2 & $12.50 \%$ & 0.001525 & 0.0299 & $\begin{array}{l}\text { Receptor } \\
\text { signaling }\end{array}$ \\
\hline & $\begin{array}{l}\text { TGFBR } \\
\text { ATF/GADD/MAX/TP53 } \\
\text { signaling }\end{array}$ & 17 & 2 & $11.76 \%$ & 0.001725 & 0.0294 & $\begin{array}{l}\text { Receptor } \\
\text { signaling }\end{array}$ \\
\hline & $\begin{array}{l}\text { TGFBR } \rightarrow \text { CREB/ELK-SRF } \\
\text { signaling }\end{array}$ & 18 & 2 & $11.11 \%$ & 0.001938 & 0.0290 & $\begin{array}{l}\text { Receptor } \\
\text { signaling }\end{array}$ \\
\hline \multirow[t]{2}{*}{ Tan } & Vitamin $\mathrm{K}$ metabolism & 36 & 2 & $5.56 \%$ & 0.001178 & 0.0202 & $\begin{array}{l}\text { Metabolic } \\
\text { pathways }\end{array}$ \\
\hline & Focal junction assembly & 37 & 3 & $8.11 \%$ & 0.001651 & 0.0179 & $\begin{array}{l}\text { Cell process } \\
\text { pathways }\end{array}$ \\
\hline \multirow[t]{2}{*}{ Turquoise } & Adipocytokine signaling & 52 & 32 & $61.54 \%$ & 0.000179 & 0.0279 & Cell signaling \\
\hline & $\begin{array}{l}\text { lipoyl-protein } \\
\text { biosynthesis }\end{array}$ & 13 & 4 & $30.77 \%$ & 0.002001 & 0.0098 & $\begin{array}{l}\text { Metabolic } \\
\text { pathways }\end{array}$ \\
\hline
\end{tabular}


In the early stages of liver regeneration, the hepatocellular transport pathway towards degradation (the late endosomes and lysosomal pathway) subsides, but transcytosis and the secretion of several major proteins in bile increase (Fernández et al., 2004). The "cyan" module with 41 genes shows enrichment of IL-6 and promotes inflammation. It is well known that IL-6 is a pleiotropic cytokine with a pivotal role in normal hepatic growth and liver regeneration (Streetz et al., 2000; Suh et al., 2008). The "midnightblue" module containing 39 genes shows enrichment in EphrinR $\rightarrow$ actin signaling, melanogenesis, and T-cell receptor signaling. The regeneration of the liver after partial hepatectomy is accompanied by a large increase in the numbers of T-cell receptor intermediates, mainly NK-like T cells (Minagawa et al., 2000). The "blue" module with 249 genes shows enrichment in the metabolism of estrogens and androgens. Previous reports have shown that cyclin D1 can directly enhance estrogen receptor activity and inhibit androgen receptor activity in a ligand-independent manner. Indeed, hepatic expression of cyclin D1 leads to increased serum estradiol levels, increased estrogen-responsive gene expression, and decreased androgen-responsive gene expression in regenerating liver (Mullany et al., 2010). The "black" module containing 91 genes shows enrichment in tight junction assembly and cell cycle regulation. Tight junction proteins of hepatocytes are regulated by various cytokines and growth factors via distinct signal transduction pathways. They are also considered to participate in signal transduction pathways that regulate epithelial cell proliferation, gene expression, differentiation, and morphogenesis (Kojima et al., 2009).

The "green" module with 109 genes shows enrichment of vitamin B5 (pantothenate) metabolism and biosynthesis of CoA and holo-ACP, immunoglobulin class-switch recombination and double-strand DNA homologous repair.

The "brown" module containing 180 genes shows enrichment in adipocytokine signaling and glycogen metabolism. It suggests that the expression patterns of the "turquoise" and "brown" modules are different and may be regulated by common upstream regulators. It is clear that maximum DNA synthesis occurs after partial hepatectomy in rat livers, and there is maximum glycogen depletion (Lea et al., 1972). The "red" module with 97 genes shows increased Golgi transport. The "lightcyan" module includes tight junction regulation. The "purple" module with 57 genes shows enrichment in IL-6 insulin resistance. IL-6 is one of several proinflammatory cytokines that have been associated with insulin resistance (Senn et al., 2002). IL-6 plays a direct role in insulin resistance at the cellular level in both primary hepatocytes and HepG2 cell lines, and may contribute to insulin resistance in LR (Streetz et al., 2000).

The "tan" module containing 52 genes shows enrichment in vitamin $\mathrm{K}$ metabolism and focal junction assembly. A full list of enriched pathways in these modules is provided in Table S3, and all pathways mentioned in this section are highlighted in yellow background to facilitate searching.

The pathway-enrichment analysis described above demonstrates that many known biological pathways are enriched in the co-expression modules. Although other top-ranked pathways closely related to LR are significantly enriched in most modules, the roles of the pathways in LR remain unclear.

\section{DISCUSSION}

In this study, we analyzed high temporal resolution rat LR gene expression data from nine time points regenerating liver after $2 / 3 \mathrm{PH}$, and identified $1772 \mathrm{DE}$ genes that enriched currently known LR-related biological processes. These genes can therefore be used as a reference gene set for new pathway and key regulator identification. 
To probe the key molecular mechanisms underlying LR, we constructed a rat liver regeneration gene co-expression network topology. One important end product of the coexpression network is gene modules comprising highly interconnected sets of genes. It has been demonstrated that these modules are generally enriched for known biological pathways. To identify the modules of highly co-regulated genes, we used average linkage hierarchical clustering to group genes based on the TO, followed by a dynamic cut-tree algorithm to dynamically cut clustering dendrogram branches into gene modules (Langfelder et al., 2008). Next, we identified 13 LR-specific gene modules based on Fisher exact test $P$ values of pairwise modules between the $\mathrm{PH}$ and $\mathrm{SO}$ groups. Gene set-enrichment analysis was then implemented for these LR-specific modules. Some of the top-enriched pathways were in agreement with our existing knowledge. For example, top-enriched cell cycle regulation in the "black" module and TGFBR-related pathways in the "salmon" module suggest potentially important roles in LR. Notably, we also found that IL-6 and adipocytokine signaling bear a close resemblance to the previously identified important pathways in rat regenerative hepatocytes. Cross-studies indicate that these biological pathways play an important role in rat LR. We also found several signaling pathways in the top-enriched pathways that have not been reported to play a role in LR.

This is the first time that co-expression network analysis has been used to analyze mRNA expression data from rat livers during LR. Our results show that WGCNA methods can provide reliable data at both tissue and cellular levels. Although further enhancements are required, we have achieved a discreet improvement.

\section{Conflicts of interest}

The authors declare no conflict of interest.

\section{ACKNOWLEDGMENTS}

Research supported by the Natural Science Foundation of Henan (\#122300410355), the National Basic Research "973" Pre-Research Program of China (\#2012CB722304), and the National Science Found of China (\#31201093, \#60873104, and \#61370169). We also thank Prof. Y.F. Jia for comments and Dr. Y. Jiang for proofreading the manuscript text.

\section{REFERENCES}

Chen L, Liu R, Liu ZP, Li M, et al. (2012). Detecting early-warning signals for sudden deterioration of complex diseases by dynamical network biomarkers. Sci. Rep. 2: 342.http://dx.doi.org/10.1038/srep00342

Fausto N and Riehle KJ (2005). Mechanisms of liver regeneration and their clinical implications. J. Hepatobiliary Pancreat. Surg. 12: 181-189.http://dx.doi.org/10.1007/s00534-005-0979-y

Fausto N, Campbell JS and Riehle KJ (2006). Liver regeneration. Hepatology 43 (Suppl 1): S45-S53.http://dx.doi.org/10.1002/ $\underline{\text { hep.20969 }}$

Fernández MA, Turró S, Ingelmo-Torres M, Enrich C, et al. (2004). Intracellular trafficking during liver regeneration. Alterations in late endocytic and transcytotic pathways. J. Hepatol. 40: 132-139.http://dx.doi.org/10.1016/j.jhep.2003.09.024

Gargalovic PS, Imura M, Zhang B, Gharavi NM, et al. (2006). Identification of inflammatory gene modules based on variations of human endothelial cell responses to oxidized lipids. Proc. Natl. Acad. Sci. USA 103: 12741-12746.http://dx.doi. org/10.1073/pnas.0605457103

Haga J, Shimazu M, Wakabayashi G, Tanabe M, et al. (2008). Liver regeneration in donors and adult recipients after living donor liver transplantation. Liver Transpl. 14: 1718-1724.http://dx.doi.org/10.1002/lt.21622 
He D, Liu ZP and Chen L (2011). Identification of dysfunctional modules and disease genes in congenital heart disease by a network-based approach. BMC Genomics 12: 592.http://dx.doi.org/10.1186/1471-2164-12-592

He D, Liu ZP, Honda M, Kaneko S, et al. (2012). Coexpression network analysis in chronic hepatitis B and C hepatic lesions reveals distinct patterns of disease progression to hepatocellular carcinoma. J. Mol. Cell Biol. 4: 140-152.http://dx.doi. org/10.1093/jmcb/mjs011

Horvath S and Dong J (2008). Geometric interpretation of gene coexpression network analysis. PLOS Comput. Biol. 4: e1000117.http://dx.doi.org/10.1371/journal.pcbi.1000117

limuro Y, Seki E, Son G, Tsutsui H, et al. (2007). Role of innate immune response in liver regeneration. J. Gastroenterol. Hepatol. 22 (Suppl 1): S57-S58.http://dx.doi.org/10.1111/j.1440-1746.2006.04651.x

Kiddle SJ, Windram OP, McHattie S, Mead A, et al. (2010). Temporal clustering by affinity propagation reveals transcriptional modules in Arabidopsis thaliana. Bioinformatics 26: 355-362.http://dx.doi.org/10.1093/bioinformatics/btp673

Knepp JH, Geahr MA, Forman MS and Valsamakis A (2003). Comparison of automated and manual nucleic acid extraction methods for detection of enterovirus RNA. J. Clin. Microbiol. 41: 3532-3536.http://dx.doi.org/10.1128/JCM.41.8.3532$\underline{3536.2003}$

Kojima T, Murata M, Yamamoto T, Lan M, et al. (2009). Tight junction proteins and signal transduction pathways in hepatocytes. Histol. Histopathol. 24: 1463-1472.

Langfelder P, Zhang B and Horvath S (2008). Defining clusters from a hierarchical cluster tree: the Dynamic Tree Cut package for R. Bioinformatics 24: 719-720.http://dx.doi.org/10.1093/bioinformatics/btm563

Lea MA, Murphy P and Morris HP (1972). Glycogen metabolism in regenerating liver and liver neoplasms. Cancer Res. 32: 61-66.

MacLennan NK, Dong J, Aten JE, Horvath S, et al. (2009). Weighted gene co-expression network analysis identifies biomarkers in glycerol kinase deficient mice. Mol. Genet. Metab. 98: 203-214.http://dx.doi.org/10.1016/j.ymgme.2009.05.004

Michalopoulos GK (2007). Liver regeneration. J. Cell. Physiol. 213: 286-300.http://dx.doi.org/10.1002/jcp.21172

Minagawa M, Oya H, Yamamoto S, Shimizu T, et al. (2000). Intensive expansion of natural killer T cells in the early phase of hepatocyte regeneration after partial hepatectomy in mice and its association with sympathetic nerve activation. Hepatology 31: 907-915.http://dx.doi.org/10.1053/he.2000.5850

Mullany LK, Hanse EA, Romano A, Blomquist CH, et al. (2010). Cyclin D1 regulates hepatic estrogen and androgen metabolism. Am. J. Physiol. Gastrointest. Liver Physiol. 298: G884-G895.http://dx.doi.org/10.1152/ajpgi.00471.2009

Ravasz E, Somera AL, Mongru DA, Oltvai ZN, et al. (2002). Hierarchical organization of modularity in metabolic networks. Science 297: 1551-1555.http://dx.doi.org/10.1126/science.1073374

Ruan J, Dean AK and Zhang W (2010). A general co-expression network-based approach to gene expression analysis: comparison and applications. BMC Syst. Biol. 4: 8.http://dx.doi.org/10.1186/1752-0509-4-8

Schadt EE, Lamb J, Yang X, Zhu J, et al. (2005). An integrative genomics approach to infer causal associations between gene expression and disease. Nat. Genet. 37: 710-717.http://dx.doi.org/10.1038/ng1589

Segal E, Shapira M, Regev A, Pe'er D, et al. (2003). Module networks: identifying regulatory modules and their conditionspecific regulators from gene expression data. Nat. Genet. 34: 166-176.http://dx.doi.org/10.1038/ng1165

Senn JJ, Klover PJ, Nowak IA and Mooney RA (2002). Interleukin-6 induces cellular insulin resistance in hepatocytes. Diabetes 51: 3391-3399.http://dx.doi.org/10.2337/diabetes.51.12.3391

Smyth GK (2004). Linear models and empirical Bayes methods for assessing differential expression in microarray experiments. Stat. Appl. Genet. Mol. Biol. 3: Article3.

Streetz KL, Luedde T, Manns MP and Trautwein C (2000). Interleukin 6 and liver regeneration. Gut 47: 309-312.http://dx.doi. org/10.1136/gut.47.2.309

Suh HN, Lee SH, Lee MY, Lee YJ, et al. (2008). Role of interleukin-6 in the control of DNA synthesis of hepatocytes: involvement of PKC, p44/42 MAPKs, and PPARdelta. Cell. Physiol. Biochem. 22: 673-684.http://dx.doi.org/10.1159/000185551

Taub R (2004). Liver regeneration: from myth to mechanism. Nat. Rev. Mol. Cell Biol. 5: 836-847.http://dx.doi.org/10.1038/ $\underline{\mathrm{nrm} 1489}$

Togo S, Makino H, Kobayashi T, Morita T, et al. (2004). Mechanism of liver regeneration after partial hepatectomy using mouse cDNA microarray. J. Hepatol. 40: 464-471.http://dx.doi.org/10.1016/j.jhep.2003.11.005

Xu CS, Jiang Y, Zhang LX, Chang CF, et al. (2012). The role of Kupffer cells in rat liver regeneration revealed by cell-specific microarray analysis. J. Cell. Biochem. 113: 229-237.http://dx.doi.org/10.1002/jcb.23348

Zhang B and Horvath S (2005). A general framework for weighted gene co-expression network analysis. Stat. Appl. Genet. Mol. Biol. 4: Article17.

Zhou Y, Xu J, Liu Y, Li J, et al. (2014). Rat hepatocytes weighted gene co-expression network analysis identifies specific modules and hub genes related to liver regeneration after partial hepatectomy. PLoS One 9: e94868.http://dx.doi. org/10.1371/journal.pone.0094868 


\section{Supplementary material}

Table S1. Differentially expressed genes between the $\mathrm{PH}$ group and the SO group.

http://www.geneticsmr.com/year2016/vol15-1/pdf/gmr7596 ts1.xls

Table S2. Module composition in the PH group and the SO group.

http://www.geneticsmr.com/year2016/vol15-1/pdf/gmr7596 ts2.xls

Table S3. Detailed pathways enriched in LR-related modules.

http://www.geneticsmr.com/year2016/vol15-1/pdf/gmr7596 ts3.xls 